\title{
Development of Self-Efficacy Belief Scale for Planning and Organizing Educational Trips to Out of School Settings ${ }^{*}$
}

\author{
Aykut Emre BOZDOĞAN**
}

Received: 16 February 2015

Accepted: 07 April 2015

\begin{abstract}
The aim of this research study was to develop a scale for self-efficacy beliefs in planning and organizing educational trips to out of school environments. First of all, relevant literature on developing a scale was reviewed in this stage. Within this context, the researcher identified total 45 initial items. The draft scale consisting of total 39 items for pre-implementation stage was administered to 358 pre-service teachers in their fourth year in Giresun Education Faculty in 2013-2014 academic years. As a result of the analysis, total 9 items were excluded from the scale. Validity analysis of the scale was performed and it was found that the factor loadings of the 30 items before being exposed to rotation were between 0.46 and 0.71 . It was also detected that the scale's item-total correlation coefficients changed between 0.58 and 0.76 . Moreover, total explained variance of the scale was determined to be $50.97 \%$. As a result of the reliability analysis, the scale’s Cronbach’s Alpha reliability coefficient was calculated to be 0.93 , Guttmann Split-Half value was calculated as 0.89 and Spearman Brown reliability coefficient was computed to be 0.89 .
\end{abstract}

Keywords: self-efficacy, educational field trip, out of school environments

\section{Extended Abstract}

Purpose and Significance: The aim of this research study was to develop a scale for self-efficacy beliefs in planning and organizing educational trips to out of school environments. It is considered that the scale will make contributions to literature because it will determine pre-service teachers and teachers' self-efficacy to organize educational trips to out of school settings and take action to make up for weaknesses; therefore, it will contribute to filling the gaps in literature.

Methods: This study is a general survey study which is intended to develop a scale. In the study conducted, this model is preferred because a scale which can be used to identify self-efficacy beliefs in planning and organizing educational trips to out of school environments is aimed at developing.

The scale was developed by following stages. The stage of generating an item pool; relevant literature on developing a scale was reviewed in this stage and measurement

\footnotetext{
* This study was supported by Giresun University Scientific Research Projects Unit. Project Code: EGT-BAP-A250414-35

** Corresponding Author: Assoc. Prof. Dr., Gaziosmanpaşa University, Tokat, Turkey, aykutemre@gmail.com
}

\section{Citation Information}

Bozdoğan, A. E. (2016). Okul dışı çevrelere eğitim amaçlı gezi düzenleyebilme öz-yeterlik inancı ölçeğinin geliştirilmesi. Kuramsal Ĕgitimbilim Dergisi [Journal of Theoretical Educational Science], 9(1), 111-129. 
tools used in the previous studies were examined so that they could help to work out how to develop the scale. While generating the items in the scale, the following actions were taken: there are equal numbers of positively and negatively worded items, items should be intelligible and simple, and an item should not include more than one judgement/opinion/ perception. Moreover, while writing scale items, things to do before the trip (18 items), things to do during the trip (17 items) and things to do after the trip (10 items) were taken into consideration when planning a trip with an educational intent to out of school settings and special attention was paid while generating expressions reflecting each stage of the trip. Within this context, the researcher identified total 45 initial items (24 positive and 21 negative). Then, the researcher decided on a scale. The scale selected was a Likert type scale as it provided an opportunity to measure selfefficacy beliefs to organize educational trips to out of school environments in the most direct and simplest way and also it had five ordered response levels because it was more reliable, valid and useful. The stage of getting an expert opinion (content validity); the opinions of two field experts, a teacher, and an expert in linguistics were consulted regarding 45 initial items. These experts examined whether the items in the scale measured self-efficacy beliefs to organize educational trips to out of school settings and whether the statements and expressions were intelligible or not. As a result of expert opinions, only 39 items from the item pool consisting of 45 items were considered appropriate and they were selected to be used as self-efficacy statements. In preimplementation stage; the draft scale consisting of total 39 items (21 positive and 18 negative statements) for pre-implementation stage was administered to 375 pre-service teachers in their fourth year in Giresun Education Faculty in 2013-2014 academic years; however, the data of 17 pre-service teachers who did not fill out the measurement tool completely or left blank were not included in analysis procedure.

Results: Exploratory factor analysis was carried out to examine the construct validity of the scale in the calculating and evaluating validity (construct validity). First of all, Kaiser-Meyer-Olkin (KMO) coefficient was conducted to test the efficiency of the population of the study so that the appropriateness of data for factor analysis could be decided. The scale's Kaiser-Mayer-Olkin (KMO) value was found to be 0.925 . This value indicates that the efficiency of the population of the study is considered perfect. Furthermore, the Barlett's test yielded a significant result as $\mathrm{p}<0.001$. The significance value calculated reveals that the values obtained from the population have equal variances of distributions.

As a result of the analysis, total 9 items having factor loadings below 0.45 (items 2, 3, 4, 7, 11, 16, 27, 29 and 33) were excluded from the scale. The remaining 30 items were not exposed to rotation and their factor loadings were found to be between 0.46 and 0.71. Moreover, it was found that 30 items included in the scale fell into five factors and the percentage of total variance for five factors accounted for $50.97 \%$. However, it was considered that the scale would have one factor due to too much difference between the variances which the first factor and the other factors accounted for. Therefore, it was 
decided that line graph drawn according to the eigen value should be examined. When the line graph drawn according to the eigen value is examined, the factor which has the fastest decrease is the first factor. The following indicators are the reasons for the scale to be one dimensional: the eigen value for the first component (9.622) was five times higher than the eigen value for the second component (1.882), there is not a significant difference between the second and subsequent eigen values (1.496, 1.198, 1.096 respectively), the percentage of variance which all the components accounted for as $50.97 \%$ was explained by the first dimension which accounted for $32.07 \%$ of the variance, and the percentage of variance accounted for was $30 \%$ or more would be enough.

The reliability analysis carried out for the scale consisting of 30 items (17 positive and 13 negative) revealed that Cronbach's alpha coefficient was found to be 0.93, Guttmann Split-Half value was 0.89, and Spearman Brown coefficient was 0.89. The reliability coefficient for the scale was found to be quite close to 1 and this reveals that the items in the scale were consistent with each other and the scale consisted of items which examined the components of the same features. In other words, it means that the reliability of the scale is quite high. Furthermore, item analysis based on the correlations between the items was conducted to measure the internal consistency of the scale. The item-total correlations of the scale varied between 0.58 and 0.76 and this finding reveals that the scale has a consistency concerning scale construction with items.

Discussions and Conclusions: This study aimed at developing a valid and reliable measurement tool to determine the self-efficacy beliefs to plan and organize educational trips to out of school environments. The scale developed will be administered to primary and secondary school teachers to explore their self-efficacy beliefs to design trips with an educational intent to out of school settings and also the scale will enable teachers to gain knowledge about their self-efficacy on the topic and will make contributions to their professional development. Therefore, it is anticipated that integrating informal learning settings actively and effectively into teaching-learning process will bring benefits. Moreover, it is considered that administering the scale to pre-service teachers and exploring their self-efficacy beliefs to organize educational trips to out of school environments will eliminate their weaknesses and satisfy their needs within the context of Elective Courses in undergraduate studies. Moreover, this scale can be used on teachers and pre-service teachers together with different variables and scales in other research studies. Finally, it is considered that the research which will use this scale will make important contributions to benefiting from out of school settings in education. 


\title{
Okul Dışı Çevrelere Eğitim Amaçlı Gezi Düzenleyebilme Öz-Yeterlik İnancı Ölçeğinin Geliştirilmesi*
}

\author{
Aykut Emre BOZDOĞAN ${ }^{* *}$
}

Makale Gönderme Tarihi: 16 Şubat 2015

Makale Kabul Tarihi: 07 Nisan 2015

\begin{abstract}
ÖZ: Bu çalışmanın amacı, okul dışı çevrelere eğitim amaçlı gezi düzenleyebilme öz-yeterlik inancına yönelik bir ölçek geliştirilmesidir. Bu kapsamda öncelikle literatür taraması yapılmış ve 45 maddeden oluşan bir taslak ölçek hazırlanmıştır. Kapsam geçerliği sonucunda 39 maddeye düşürülen taslak ölçek 2013-2014 öğretim yılında Giresun Üniversitesi Eğitim Fakültesinde öğrenim gören 358 öğretmen adayına uygulanmıştır. Açımlayıcı faktör analizi sonucunda taslak ölçekten 9 madde çıkarılmıştır. Ölçek maddelerinin rotasyona tabi tutulmaksızın faktör yüklerinin 0.46 ile 0.71 arasında olduğu görülmüştür. Ölçeğin madde-toplam korelasyon katsayılarının 0.58 ile 0.76 arasında değiştiği görülmüştür. Ölçekte kalan 30 maddenin açıkladıkları toplam varyansın \%50.97 olduğu tespit edilmiştir. Ölçeğin Cronbach Alfa güvenilirlik katsayısı 0,93; Guttmann Split-Half değeri 0.89 ve Spearman Brown güvenirlik katsayısı da 0.89 olarak hesaplanmıştır.
\end{abstract}

Anahtar kelimeler: öz-yeterlilik, eğitim amaçlı alan gezileri, okul dışı çevreler

\section{Giriș}

Günümüz eğitim sistemleri, bireylerin kendi ihtiyaçlarını karşılayabilen, bağımsız yaşayabilme becerilerine sahip olan, araştıran, eleştirel düşünebilen ve karşılaştığı bütün problemleri çözmede bilimsel metodu kullanabilen bireyler yetiştirebilmek için planlanmaktadır. Bu davranışların kazandırılmasında okullarda geçirilen öğrenme yaşantılarıyla beraber okul dışı öğrenme ortamlarında sağlanan deneyimlerin de etkisi her geçen gün artmaktadır. Bu kapsamda günümüz eğitim ve ögretim faaliyetleri evde, okulda, işyerinde ve mümkün olan her yerde ve her firsatta yaşam boyunca devam eden bir sürece dönüşmüştür.

İnformal eğitim çevreleri olarak nitelendirilen bu yerler televizyon, radyo, gazete, dergi, internet gibi kitle iletişim araçlarını, spor merkezlerini, hayvanat bahçelerini, botanik parklarını, ormanlık arazileri, müzeleri, kütüphaneleri, akvaryumları, açık hava laboratuvarlarını, doğa merkezlerini (mağaralar, göller, akarsular, sahil alanları vs.), kampları, fabrikaları, evleri ve daha sayamayacağımız birçok toplumsal alanı kapsamaktadır (Hannu, 1993; Howe \& Disinger, 1988). İnformal eğitim çevrelerinde verilen eğitimin formal eğitim çevrelerine göre daha esnek, eğlenceli ve doğal olması ve farklı aktivitelerle her yaştan kişiye öğrenme ve farklı deneyimler kazandırma imkânı sunması avantaj olarak görülebilir (Taylor \& Caldarelli, 2004). Yapılan araştırmalar formal eğitim kaynakları dışında sunulan farklı etkinliklerin öğrenmeyi daha verimli hale getiren zengin öğretim kaynakları olduğunu (RameyGassert, 1997), sınıf ortamının ortaya koyamadığı uygulamalarla öğrenmeyi cesaretlendirdiğini, her öğrencinin kendi hızında bilgilenmesine yardımcı olduğunu

\footnotetext{
* Bu çalışma Giresun Üniversitesi BAP birimi tarafindan desteklenmiştir. Proje kodu: EGT-BAP-A-250414-35

*** Sorumlu Yazar: Doç. Dr., Gaziosmanpaşa Üniversitesi, Tokat, Türkiye, aykutemre@gmail.com
} 
(Melber \& Abraham, 1999) ve okuldaki eğitimi desteklediğini ortaya koymuştur (Gerber, Cavallo \& Marek, 2001; Hannu, 1993).

Birçok alanı içeren informal eğitim çevrelerinden birisi de okul dişı çevrelere düzenlenen gezileridir. Çocukların eğitimi için özgür ve yenilikçi bir eğitim ortamı sağlayan okul dişı çevrelerde yapılan eğitim öğretim faaliyetleri (Berberoğlu \& Uygun, 2013) okulda yapılan eğitim-öğretim faaliyetlerin destekler ve zenginleştirir. Bu ortamlar öğrencilere yaparak yaşayarak öğrenme fırsatı sunmakta, beş temel duyusunu kullanmasına firsat vermekte ve kalıcı öğrenmelerine imkân sağlamaktadır (Tatar \& Bağrıyanık, 2012; Yavuz \& Kıyıcı, 2012). Öğrencilerin fabrika, müze, kütüphane, çeşitli devlet kurumları, dağ, orman, göl, akarsu gibi okul dışı çevrelere yapacakları geziler öğretimi kitaba bağımlılıktan ve sınıf atmosferinden kurtarmakta ve farklı deneyimler sağlamaktadır. Çocuklar eğitim-öğretim etkinlikleriyle ait oldukları topluma ve sosyal yaşama öğrenci olarak katıldıklarında sorumluluklarının bilincine daha fazla varabilir (Demir, 2007a; Özgen, 2011).Okul dışı çevrelere yapılan gezilerin eğlenceli ve heyecan verici (Tortop \& Özek, 2013) olmasından dolayı öğrencilerin öğrenmelerini kalıcı hale getirmek, aynı zamanda bilişsel, duyuşsal, sosyal ve psikomotor becerilerindeki gelişimini artırmak için çok önemli yerler olduğu vurgulanmaktadır (Demirbaş, 2005; DeWitt \& Storksdieck, 2008; Dillon \& diğ., 2006; Lakin, 2006; Berberoğlu \& diğ., 2013; Tatar \& Bağrıyanık, 2012). Yapılan çalışmalar okul dış1 çevrelere düzenlenen planlı gezilerin ögrencilerin bilgi, tutum ve davranışlarına olumlu yönde etki ettiğini ortaya koymaktadır (Ballantyne \& Packer, 2009; Bozdoğan, 2007; Bozdoğan \& Yalçın, 2006; Göğebakan, 2008; Güler, 2011; Kete \& Horasan, 2013; Knapp \& Barrie, 2001; Orion \& Hofstein, 1994; Orion, Hofstein, Tamir \& Giddings, 1997; Özgen, 2011; Rudman, 1994; Tal \& Morag, 2009; Yavuz \& K1yıc1, 2012).

Öğrenciler için birçok önemli avantajları olan okul dışı çevrelere yapılacak gezilerin amaçlarına ulaşması için planlama, uygulama ve değerlendirme aşamaları çok hassasiyet gerektiren bir iştir (Bozdoğan, 2012; Demir, 2007b; Ertaş \& Parmasızoğlu, 2011). Çünkü yapılan çalışmalarda iyi planlanmış ve okul müfredatıyla iyi ilişkilendirilmiş alan gezilerinin başarılı sonuçlar vereceği vurgulanmıştır (Bowker \& Tearle, 2007; Kisiel, 2005; Tal, Bamberger \& Morag, 2005). Bu süreçte öğretmenlere büyük görevler düşmektedir. Öğretmenlerin gezi düzenleme sürecinde isteklilikleri, sorumlulukları ve duyarlılıkları azami derecede olmalı ve başarılı bir gezi için çaba göstermeleri gerekmektedir (Demir, 2007a; Kete \& Horasan, 2013). Ancak okul dış1 mekânlar öğretmenler, program geliştirmeciler ve araştırmacılar tarafından en fazla göz ard1 edilen eğitim ortamlarıdır (Orion \& Hofstein, 1994). Yapılan çalışmalar öğretmenlerin okul dışı ortamlardaki eğitim aktivitelerinin öğrencilerin öğrenmelerinde etkili olduğunu düşündüklerini ancak bu aktiviteleri en az düzeyde tercih ettiklerini ortaya koymuştur (Carrier, 2009; Güven, Gazel \& Sever, 2004; Moseley, Reinke \& Bookout, 2002; Orion \& diğ., 1997; Simmons, 1998; Tatar \& Bağrıyanık, 2012). Bunun nedenleri ise, öğretmenlerin alan gezilerini gerçekleştirirken yönetimsel, rehberlik ve pedagojik anlamda çeşitli zorluklarla karşılaşmaları (Griffin \& Symington 1997; Kisiel 2003; Michie, 1998; Olson, Cox-Petersen \& McComas, 2001; Tal \& Morag, 2009; Tal 
\& Steiner 2006), alan gezisi sürecinde aktif rol almadıkları, alan gezileri için yapılması gereken planlama konusunda hiç bir fikre sahip olmadıkları (Anderson, Bethan \& Mayer-Smith, 2006; Bozdoğan, 2012; Demir, 2007a; Ferry 1993; Tal 2004; Tal, Bamberger \& Morag; 2005) ve öğrencileri yönlendirme konusunda yetersiz oldukları (Cox-Petersen \& Pfaffinger, 1998; Griffin \& Symington, 1997; Kisiel, 2005; Wellington, 1990) olarak sıralanmıştır. Bu eksikliklerin giderilmesi içinse öğretmenlere uygulamalı hizmet içi eğitim seminerleriyle, öğretmen adaylarına da lisans düzeyinde dersler ve projelerle okul dişı çevrelerde eğitimin nasıl yapılacağına yönelik bilgi ve beceriler kazandırılması gerektiği belirtilmiştir (Bozdoğan, 2012; Tatar \& Bağrıyanık, 2012, Türkmen, 2010). Görüldüğü gibi yapılan çalışmalar okul dış1 çevrelere eğitim amaçlı geziler düzenleme sürecinde öğretmenlerin birçok sorunla karşılaştıklarını göstermekte; bu sorunların çözümü için öğretmen ve öğretmen adaylarına profesyonel eğitim verilmesinin önemini ortaya koymaktadır. Öğretmen adaylarına verilecek profesyonel destek kapsamında öncelikle bu çevrelere gezi düzenleyebilme öz yeterliklerinin ortaya konması ve bu veriler ışığında bir plan çizilmesi gerekir.

Öz yeterlilik düzeyi bireylerin olay, durum ve zor süreçlerde nasıl davrandıklarını belirleyen önemli bir etkendir (Yaman, Cansüngü \& Altunçekiç, 2004). Kişide öz yeterlilik inancı ne oranda yüksek ise onda o oranda çaba, ısrar ve direnç görülür. Öz yeterliği düşük olan kişiler ise olayların göründüğünden zor olduğu kanısındadırlar ve dar bakış açısı ile baktıklarından problemlerini ya da çalışmalarını başarı ile tamamlayamazlar (Kaptan \& Korkmaz, 2002). Özellikle öğretmenlerin öz yeterlilik inanç düzeylerinin sınıf içindeki performansları ve uygulamaları etkilediği ve öz yeterliliği yüksek düzeyde olan öğretmelerin öğretim konusunda daha arzulu ve tutkulu olduğu ortaya çıkmıştır (Tuckman \& Sexton, 1990).

Bu kapsamda literatür incelendiğinde öğretmen adaylarının ya da öğretmenlerin okul dışı çevrelere eğitim amaçlı gezi düzenleyebilme öz-yeterlik inancını ölçen bir ölçeğin olmadığı görülmektedir. Bu kapsamda yapılan bu çalışmada okul dışı çevrelere eğitim amaçlı gezi düzenleyebilme öz-yeterlik inancı ölçeğinin geliştirilmesi amaçlanmıştır. Geliştirilen bu ölçeğin öğretmen adaylarının ve öğretmenlerin okul dış1 çevrelere eğitim amaçlı gezi düzenleyebilme öz-yeterliklerinin tespit edilmesi ve bu kapsamda eksikliklerinin giderilmesi için gerekli adımların atılması noktasında literatürdeki bu boşluğu doldurarak katkı sağlayacağı düşünülmektedir.

\section{Yöntem}

$\mathrm{Bu}$ çalışma, ölçek geliştirmeyi amaçlayan bir genel tarama çalışmasıdır. Tarama çalışmaları büyük bir topluluğun bir konuya ilişkin görüşlerini ya da inanç, tutum, ilgi vs. gibi özellikleri betimlenmeyi amaçlayan bir araştırma modelidir (Büyüköztürk, 2012; Karasar, 1999). Yapılan çalışmada da okul dış1 çevrelere eğitim amaçlı gezi düzenleyebilme öz-yeterlik inancının betimlenmesinde kullanılacak bir ölçeğinin geliştirilmesi amaçlandığı için bu model kullanılmıştır. 


\section{Çalışma Grubu}

$\mathrm{Bu}$ araştırmanın çalışma grubunu; 2013-2014 öğretim yılında Giresun Eğitim Fakültesi 4. sınıflarında öğrenim gören 212'si kadın 146'sı erkek toplam 358 öğretmen adayı oluşturmaktadır.

\section{Ölçeğin Geliştirilme Aşaması}

Genel olarak ölçme araçlarının geliştirilmesinde izlenmesi gereken Madde oluşturma, Uzman görüşü alma, Ön uygulama ve Geçerlik ve Güvenirlik Hesaplamaları aşamaları takip edilmiştir (Balc1, 2005; Karasar, 1999).

Madde havuzu oluşturma aşaması. Bu aşamada ilk olarak ölçek geliştirme ile ilgili literatür taraması yapılmış ve geliştirilecek ölçeğin nasıl hazırlanması gerektiği konusunda rehber olması amacıyla daha önceki çalışmalarda kullanılan ölçme araçları incelenmiştir (Aydın, İnnalı, Batar \& Çakır, 2013; Başer, 2007; Bekdemir \& Duran, 2012; Bektaş, 2007; Bozdoğan \& Öztürk, 2008; Ekici, Taşkın Ekici \& Kara, 2012; Hacıfazlıoğlu, Karadeniz \& Dalgıç, 2011; Kılıç \& İncikabı, 2013; Mercimek \& Pektaş, 2013; Özdemir, Aydın \& Akar Vural, 2009; Öztürk, 2008; Şahin, 2009).

Ölçek maddeleri hazırlanırken; maddelerin eşit sayıda olumlu ve olumsuz olarak ifade edilmesine; sade ve anlaşılır olmasına; bir maddenin birden fazla yargı/düşünce/duyuş içermemesine dikkat edilmiştir. Yine ölçek maddeleri oluşturulurken okul dışı çevrelere eğitim amaçlı gezi düzenleme sürecindeki gezi öncesi yapılacak işlemler (18 madde), gezi esnasında yapılacak işlemler (17 madde) ve gezi sonrası yapılacak işlemler (10 madde) göz önünde bulundurarak her bir işlemi yansıtan ifadeler yer almasına dikkat edilmiştir. Bu kapsamda araştırmacı tarafından toplam 45 (24 olumlu, 21 olumsuz) öncül madde belirlenmiştir. Daha sonra okul dişı çevrelere eğitim amaçlı gezi düzenleme öz-yeterliğini doğrudan ve en kolay şekilde ölçmeye imkân tanıması bakımından Likert tipinde, daha duyarlı ve kullanışlı olması için de 5'li şekilde derecelendirilmiş bir ölçek olmasına karar verilmiştir. Buna göre ölçekteki her bir olumlu madde "Tamamen kat1lyorum (5 puan)", "Kat1liyorum (4 puan)", "Karasızım (3 puan)", "Katılmıyorum (2 puan)" ve "Hiç katılmıyorum (1 puan)" şeklinde derecelendirilmiştir. Ölçekteki olumsuz maddelerin puanlaması ise ters olarak yapılmıştır.

Uzman görüşü alma aşaması (kapsam geçerliği). Bir ölçme aracının bireylerin davranışlarını tahmin etmedeki başarısı büyük ölçüde geçerli ve güvenilir olmasına bağlıdır (Büyüköztürk, 2012). Bu aşamada hazırlanan ölçeğin kapsam geçerliği açısından yeterliliği incelenmiştir. Kapsam geçerliği, ölçme aracında bulunan maddelerin ölçme aracına uygun olup olmadığını, ölçülmek istenen alanı temsil edip etmediğini belirlemek için uzman görüşüne başvurularak gerçekleştirilir (Karasar, 1999; Tavşancıl, 2002). Yapılan çalışmada 45 öncül maddeye ilişkin, iki alan uzmanı, bir eğitim bilimci, iki öğretmen ve bir dil alan uzmanın görüşleri alınmıştır. Bu uzmanlar ölçek maddelerinin okul dişı çevrelere eğitim amaçlı gezi düzenlemeye yönelik özyeterlik inancını ölçüp ölçmediğini, ifade ve anlatımların anlaşılabilirliğini incelemiştir. 
Uzman görüşleri sonucunda toplam 45 maddeden oluşan madde havuzundan 39 madde uygun görülmüş ve öz-yeterlik ifadesi olarak kullanılmak üzere seçilmiştir. Bu sayede hazırlanan ölçme aracının kapsam geçerliği sağlanmaya çalışılmıştır. Uzman görüşleri doğrultusunda maddeler sıralanmış, taslak ölçeğin başlangıcına kısaca çalışmanın amacı, kodlamanın nasıl yapılacağına ilişkin bir yönerge ve cevaplama seçenekleri açık bir şekilde yazılarak görünüş geçerliği de sağlanmıştır.

Ön uygulama aşaması. Ön uygulama için 21 olumlu ve 18 olumsuz ifadeden meydana gelen ve toplam 39 maddeden oluşan taslak ölçme arac1, 2013-2014 öğretim yılında Giresun Eğitim Fakültesi 4. sınıflarında öğrenim gören 375 öğretmen adayına uygulanmış ancak ölçme aracını eksik dolduran ve boş bırakan 17 öğretmen adayının verileri analiz sürecine katılmamıştır.

\section{Bulgular}

\section{Geçerlik Hesaplamaları (Yapı Geçerliği)}

Yapılan çalışmanın bu aşamasında ölçeğin yapı geçerliği incelenmiştir. Ölçeğin yap1 geçerliğini incelemek için açımlayıcı faktör analizi yapılmıştır. Büyüköztürk (2002), faktör analizini birbiri ile ilişkili değişkenleri bir araya getirerek, az sayıda ilişkisiz kavramsal olarak anlamlı yeni değişkenler (faktörler, boyutlar) keşfetmeyi amaçlayan çok değişkenli bir istatistiksel yöntem olarak tanımamaktadır.

Toplanan verilerin faktör analizine uygun olup olmadığına karar vermek için öncelikle çalışma grubunun yeterli olup olmadığına ve verilerin evrende normal dağılım gösterip göstermediğine bakılması gerekir. Çalışma grubunun yeterliliğini test etmek için Kaiser-Meyer-Olkin (KMO) katsayısına bakılmıştır. KMO katsayısı 1.00-0.90 arası mükemmel, 0.89-0.80 arası çok iyi, 0.79-0.70 arası iyi, 0.69-0.60 arası orta, 0.59-0.50 arası zayıf ve 0.49 'dan küçük değerler için kabul edilemez örneklem yeterliğini göstermektedir (Büyüköztürk, 2005; Tavşancıl, 2005). Çalışma grubundan elde edilen verilerin normal dağılım gösterip göstermediğini belirlemek için ise Bartlett testi yapılarak anlamlılık değeri incelenmiştir. Bu kapsamda Kaiser-Mayer-Olkin (KMO) ve Barlett testi sonuçları Tablo 1'de verilmiştir.

Tablo 1

Ölçeğin Kaiser-Mayer-Olkin (KMO) örneklem ölçüm ve Barlett's test sonuçları

\begin{tabular}{cccc}
\hline Kaiser-Mayer-Olkin (KMO) Örneklem Ölçüm Değer Yeterliği & 0.925 & \\
Barlett Testi Yaklaşık Ki-Kare Değeri & 4898 & sd $=741$ & $\mathrm{p}=0.000^{*}$ \\
\hline${ }^{*} p<0.001$ & &
\end{tabular}


Ölçeğin Kaiser-Mayer-Olkin (KMO) değeri 0.925 olarak bulunmuştur. Bu değer seçilen çalışma grubu yeterliğinin mükemmel olduğunu göstermektedir. Barlett testi anlamlılık değerinin $p<0.001$ olduğu tespit edilmiştir. Bulunan anlamlılık değeri çalışma grubundan elde edilen değerlerin normal dağılıma sahip olduğunu göstermektedir. Elde edilen bu değerler ölçme aracı için faktör analizinin uygulanabilirliğini göstermektedir. Faktör analizi bir ölçekteki maddelerin birbirini dışta tutan daha az sayıda faktöre ayrılıp ayrılmadığını ortaya çıkarmak için kullanılmakta olup (Balc1, 2005) bu kapsamda maddelerin faktör yük değerleri büyük öneme sahiptir. Açımlayıcı faktör analizi sonucunda, maddelerin faktör yük değerlerinin 0.45 ve üzerinde bir değerde olması ve yükü iki faktöre de dağılan maddelerin atılması gerekmektedir (Büyüköztürk, 2002; 2005).

Yapılan çalışmadaki ölçek maddeleri için açıklanan toplam varyans değerleri Tablo 2'de verilmiştir. 
Tablo 2

Ölçeğin maddeleri için açılanan toplam varyans değerleri

\begin{tabular}{|c|c|c|c|c|c|c|}
\hline \multirow{2}{*}{ Bileşenler } & \multicolumn{3}{|c|}{ Başlangıç özdeğer } & \multicolumn{3}{|c|}{ Kareler Toplamı Ekstraksiyonu } \\
\hline & Toplam & Varyans \% & Toplanmış \% & Toplam & Varyans \% & Toplanmış \% \\
\hline 1 & 9.622 & 32.072 & 32.072 & 9.622 & 32.072 & 32.072 \\
\hline 2 & 1.882 & 6.272 & 38.343 & 1.882 & 6.272 & 38.343 \\
\hline 3 & 1.496 & 4.986 & 43.329 & 1.496 & 4.986 & 43.329 \\
\hline 4 & 1.198 & 3.993 & 47.322 & 1.198 & 3.993 & 47.322 \\
\hline 5 & 1.096 & 3.654 & 50.977 & 1.096 & 3.654 & 50.977 \\
\hline 6 & .956 & 3.187 & 54.164 & & & \\
\hline 7 & .895 & 2.982 & 57.145 & & & \\
\hline 8 & .855 & 2.851 & 59.996 & & & \\
\hline 9 & .809 & 2.695 & 62.692 & & & \\
\hline 10 & .783 & 2.611 & 65.303 & & & \\
\hline 11 & .745 & 2.484 & 67.787 & & & \\
\hline 12 & .735 & 2.449 & 70.235 & & & \\
\hline 13 & .700 & 2.334 & 72.570 & & & \\
\hline 14 & .668 & 2.228 & 74.798 & & & \\
\hline 15 & .655 & 2.182 & 76.980 & & & \\
\hline 16 & .629 & 2.095 & 79.075 & & & \\
\hline 17 & .607 & 2.023 & 81.098 & & & \\
\hline 18 & .573 & 1.911 & 83.009 & & & \\
\hline 19 & .561 & 1.869 & 84.878 & & & \\
\hline 20 & .551 & 1.836 & 86.714 & & & \\
\hline 21 & .503 & 1.677 & 88.391 & & & \\
\hline 22 & .476 & 1.588 & 89.979 & & & \\
\hline 23 & .471 & 1.569 & 91.548 & & & \\
\hline 24 & .430 & 1.433 & 92.981 & & & \\
\hline 25 & .414 & 1.379 & 94.360 & & & \\
\hline 26 & .392 & 1.305 & 95.666 & & & \\
\hline 27 & .363 & 1.210 & 96.875 & & & \\
\hline 28 & .356 & 1.187 & 98.063 & & & \\
\hline 29 & .318 & 1.061 & 99.123 & & & \\
\hline 30 & .263 & .877 & 100.000 & & & \\
\hline
\end{tabular}


Ölçek maddelerinin temel bileşenler analizi sonucundaki faktör yük değerleri ve madde korelasyon değerleri Tablo 3'de verilmiştir.

Tablo 3

Ölçek maddelerinin temel bileşenler analizi sonucundaki faktör yük değerleri ve madde korelasyon değerleri

\begin{tabular}{cccccc}
\hline Madde & $\begin{array}{c}\text { Faktör } \\
\text { Yük } \\
\text { Değeri }\end{array}$ & $\begin{array}{c}\text { Madde } \\
\text { Korelasyon } \\
\text { Değeri }\end{array}$ & Madde & $\begin{array}{c}\text { Faktör Yük } \\
\text { Değeri }\end{array}$ & $\begin{array}{c}\text { Madde } \\
\text { Korelasyon } \\
\text { Değeri }\end{array}$ \\
\hline 21 & .623 & .665 & 15 & .527 & .611 \\
38 & .672 & .720 & 9 & .550 & .632 \\
26 & .638 & .705 & 39 & .543 & .645 \\
19 & .625 & .689 & 25 & .647 & .733 \\
17 & .578 & .641 & 32 & .609 & .681 \\
8 & .567 & .640 & 10 & .479 & .632 \\
37 & .706 & .759 & 35 & .570 & .626 \\
36 & .645 & .736 & 23 & .539 & .649 \\
24 & .593 & .645 & 14 & .515 & .616 \\
34 & .543 & .658 & 13 & .537 & .612 \\
30 & .570 & .688 & 12 & .532 & .622 \\
28 & .490 & .585 & 22 & .565 & .656 \\
31 & .559 & .629 & 18 & .504 & .641 \\
1 & .496 & .625 & 6 & .496 & .587 \\
20 & .516 & .619 & 5 & .460 & .596 \\
\hline
\end{tabular}

Yapılan analizler sonucunda faktör yük değeri 0.45 'in altında olan (2., 3., 4., 7, 11, 16, 27., 29. ve 33. maddeler) toplam 9 madde ölçekten çıkarılmıştır. Ölçekte kalan 30 maddenin rotasyona tabi tutulmaksızın faktör yüklerinin 0.46 ile 0.71 arasında olduğu görülmüştür. Ayrıca ölçek kapsamına alınan 30 maddenin 5 faktör altında toplandığı ve bu 5 faktörün ölçeğe ilişkin açıkladıkları toplam varyansın \%50.97 olduğu tespit edilmiştir. Sosyal bilimlerde açıklanan varyansın \%40 ile \%60 arasında olması yeterli olduğunu göstermekte olup (Çokluk, Şekercioğlu \& Büyüköztürk, 2010; Scherer \& diğ., 1988) hazırlanan ölçek için açıklanan varyans yüzdesi 40'ın üzerinde olduğundan yeterlidir. Ancak birinci faktör ile diğer faktörlerin açıkladığı varyanslar arasında çok fazla fark olması ölçme aracının tek faktörlü olabileceğini düşündürmüştür. Bu nedenle özdeğere göre çizilen çizgi grafiğinin incelenmesine karar verilmiştir. 
Grafik 1. Ölçek Maddelerinin Özdeğerlerine Ait Çizgi Grafiği

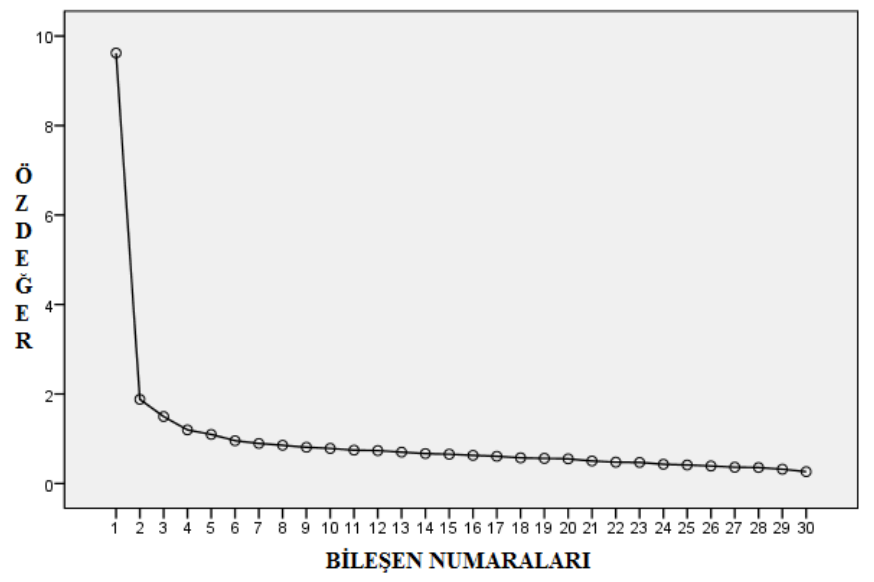

Özdeğere göre çizilen çizgi grafiğgi incelendiğinde en hızlı düşüş 1. faktördedir. Birinci bileşene ait özdeğerin (9.622) ikinci bileşene ait özdeğerden (1.882) 5 kattan fazla olması; ikincisi ile daha sonraki özdeğerler arasında da (sırasıyla 1.496, 1.198, 1.096) çok fazla bir farkın olmaması; tüm bileşenlerin açıkladığı \%50.97'luk varyansın \%32.07'lik birinci boyut ile açıklanması; bir ölçeğin tek faktörlü sayılabilmesi için birinci faktörde açıklanan varyansın yüzde 30 ve daha fazla olmasının yeterli görülmesi gibi nedenler ölçeğin tek boyutlu olduğunun göstergeleridir (Büyüköztürk, 2003; Deniz Sünbül, 2006). Zaten Temel Bileşenler analizinde maddelerin genel faktörde birleştiği (Aşkar, 1986) düşünüldüğünde de ölçeğin tek faktör üzerinde toplandığı söylenebilir.

\section{Güvenirlik Hesaplama Aşaması}

Güvenirlik, ölçeme aracının tutarlı olarak her durumda benzer sonuçlar doğurmasıdır (Bell, 1993). Gerçekleştirilen analizler sonucunda 30 (17 olumlu, 13 olumsuz) maddeden oluşan ölçek için yapılan güvenilirlik analizleri sonucunda Cronbach Alfa güvenilirlik katsayısı 0.93, Guttmann Split-Half değeri 0.89 ve Spearman Brown güvenirlik katsayısı da 0.89 olarak hesaplanmıştır. İlgi ve yetenek türü araştırmalarda kullanılacak ölçeklerin Cronbach Alfa güvenilirlik katsayısının en az 0.85 düzeyinde olması belirtilmektedir (Şencan, 2005). Bu çalışmadaki ölçeğe ait güvenilirlik katsayısının 1'e yakın çıkması ölçekte bulunan maddelerin birbiriyle tutarlı ve aynı özeliğin öğelerini yoklayan maddelerden oluştuğunu (Turan \& Demirel, 2009) yani ölçeğin oldukça yüksek bir güvenilirliğe sahip olduğunu göstermektedir. Ayrıca ölçeğin maddeler bazında iç tutarlılığını test etmek amacıyla da korelasyona dayalı madde analizi yapılmıştır. Ölçeğin madde-toplam korelasyonlarının 0.58 ile 0.76 arasında değiştiği dikkate alındığında ölçeğin maddeler bazında da tutarlı bir yapıya sahip olduğu anlaşılmaktadır (bkz. Tablo 2).

\section{Tartışma ve Sonuç}

$\mathrm{Bu}$ çalışma ile okul dışı çevrelere eğitim amaçlı gezi düzenleyebilme öz-yeterlik inancını belirlemeye yönelik geçerli ve güvenilir bir ölçme aracı geliştirilmeye çalışılmıştır. 45 maddeden oluşan taslak ölçeğin Kapsam Geçerliği sonucunda ön 
uygulama için 39 maddeye düşürülmüştür. Ön uygulama sonucunda elde edilen veriler ölçeğin geçerliği için faktör analizine tabi tutulmuştur. Açımlayıcı faktör analizi sonucunda taslak ölçekten 9 madde çıkarılmıştır. Ölçekte kalan 30 maddenin rotasyona tabi tutulmaksızın faktör yüklerinin 0.46 ile 0.71 arasında olduğu görülmüştür. Ayrıca ölçek kapsamına alınan 30 maddenin 5 faktör altında toplandığı ve bu 5 faktörün ölçeğe ilişkin açıkladıkları toplam varyansın \%50.97 olduğu tespit edilmiştir. Ancak birinci faktör ile diğer faktörlerin açıkladığı varyanslar arasında çok fazla fark olmasından ve birinci faktörde açıklanan varyansın \%32.07 olmasından dolayı ölçeğin tek faktörlü (Büyüköztürk, 2003; Deniz Sünbül, 2006) olduğuna karar verilmiştir.

Ölçeğin iç tutarlılık katsayıları; Cronbach Alpha, Sperman-Brown formülü ve Guttmann split-half güvenirlik formülü kullanılarak hesaplanmıştır. Ölçeğin Cronbach Alfa güvenilirlik katsayıs1 0.93, Guttmann Split-Half değeri 0.89 ve Spearman Brown güvenirlik katsayısı da 0.89 olarak hesaplanmıştır. Bu sonuçlar ölçeğin oldukça yüksek bir güvenilirliğe sahip olduğunu göstermektedir. Ayrıca ölçeğin maddeler bazında iç tutarlılığını test etmek amacıyla da korelasyona dayalı madde analizi yapılmıştır. Ölçeğin madde-toplam korelasyon katsayılarının 0.58 ile 0.76 arasında değiştiği görülmüştür. Buna göre ölçekte yer alan her bir maddenin, ölçeğin geneli ile ölçülmek istenen özelliği ölçebilme amacına anlamlı düzeyde hizmet ettiği ve her bir maddenin istenilen düzeyde ayırt edici olduğu söylenebilir.

Geliştirilen bu ölçeğin ilkokul, ortaokul ve lise öğretmenlerine uygulanarak okul dışı çevrelere eğitim amaçlı gezi düzenleyebilme öz-yeterliklerinin ortaya çıkarılması, onların bu konudaki yeterlikleri hakkında bilgi sahibi olmalarını sağlayarak, konu ile ilgili mesleki gelişimlerine katkıda bulunabilecektir. Böylece, okul dışı çevrelerin de öğrenme-öğretme sürecine etkili bir şekilde katılması konusunda fayda sağlanabileceği umulmaktadır. Yine geliştirilen ölçme aracının öğretmen adaylarına uygulanarak okul dışı çevrelere eğitim amaçlı gezi düzenleyebilme yeterliklerinin ortaya çıkarılmasıyla onların bu konuda varsa eksikliklerinin ve ihtiyaçlarının lisans programlarında Seçmeli Dersler kapsamında giderilmesi umulmaktadır. Aynı zamanda, bu ölçeğin öğretmenler ve öğretmen adayları üzerinde farklı değişkenlerle ve ölçeklerle beraber başka araştırmalarda kullanımı da gerçekleştirilebilir. Geliştirilen bu ölçeğin kullanılacağı araştırmalar öğretimde okul dışı çevrelerden yararlanılmasına önemli katkılar sağlayacağı düşünülmektedir.

\section{Kaynakça}

Anderson, D., Bethan, L. \& Mayer-Smith, J. (2006). Investigating the impact of practicum experience in an aquarium on preservice teachers. Teaching Education, 17, 341-353.

Aşkar, P. (1986). Matematik dersine yönelik tutumu ölçen likert tipi bir ölçeğin geliştirilmesi. Eğitim ve Bilim, 11(62), 31 - 36.

Aydın, İ. S., İnnalı, H.Ö., Batar, M. \& Çakır, H. (2013). Öğretmen adaylarının yazılı anlatım öz yeterliklerine ilişkin ölçek geliştirme çalışması. Turkish Studies, 8(8), 139-160. 
Balc1, A. (2005). Sosyal bilimlerde araştırma yöntem, teknik ve ilkeleri. Pegem Yayınevi. Ankara.

Ballantyne, R. \& Packer, J. (2009). Introducing a fifth pedagogy: Experience-based strategies for facilitating learning in natural environments. Environmental Education Research, 15(2), 243-262.

Başer, N. (2007). Geometriye yönelik öz-yeterlik ölçeğinin geliştirilmesi. Hacettepe Üniversitesi Ë̆itim Fakültesi Dergisi, 33, 68-76.

Bekdemir, M. \& Duran, M. (2012). İlköğretim öğrencileri için görsel matematik okuryazarlığı öz yeterlik algı ölçeğinin geliştirilmesi. Ondokuz Mayıs Üniversitesi Eğitim Fakültesi Dergisi, 31(1), 89-115.

Bektaş, M. (2007). Sınıf öğretmenliği öğrencilerinin hayat bilgisi öğretimine yönelik öz yeterlik algısı ölçeği. Sakarya Üniversitesi Eğitim Fakültesi Dergisi, 14, 175-183.

Bell, J., (1993). Doing your research project. (2nd. Edition). Buckingham: Open University Press.

Bowker, R. \& Tearle, P. (2007). Gardening as a learning environment: A study of children's perceptions and understanding of school gardens as part of an international project. Learning Environments Research, 10(2), 83-100.

Bozdoğan, A. E. (2007). Role and Importance of Science and Technology Museum In Education. (Unpublished doctoral dissertation). Gazi University, Enstitude of Educational Science. Ankara.

Bozdoğan, A. E. (2012). Eğitim amaçlı gezilerin planlanmasına ilişkin fen bilgisi ögretmen adaylarının uygulamaları: Altı farklı alan gezisinin değerlendirilmesi. Kuram ve Uygulamada Ĕgitim Bilimleri, 12(2), 1050-1072.

Bozdoğan, A. E. \& Yalçın, N. (2006). Bilim merkezlerinin ilköğretim öğrencilerinin fene karşı ilgi düzeylerinin değişmesine ve akademik başarılarına etkisi: enerji parkı. Ege Ĕ̈itim Dergisi, 7(2), 95- 114.

Bozdoğan, A.E. \& Öztürk, Ç. (2008). Coğrafya ile ilişkili fen konularının öğretimine yönelik öz-yeterlilik inanç ölçeğinin geliştirilmesi. Necatibey Eğitim Fakültesi Elektronik Fen ve Matematik Eğitimi Dergisi, 2(2), 66-81.

Büyüköztürk, Ş. (2002) Faktör analizi: Temel kavramlar ve ölçek geliştirmede kullanımı. Kuram ve Uygulamada Eğitim Yönetimi, 32, 470-483.

Büyüköztürk, Ş. (2003). Sosyal bilimler için veri analizi el kitabı. Pegem Yayıncılık, Ankara.

Büyüköztürk, Ş. (2012). Bilimsel araştırma yöntemleri. Pegema Yayıncılık, Ankara.

Büyüköztürk, Ş. (2005). Anket geliştirme. Türk Ĕ̆itim Bilimleri Dergisi, 3(2), 133-151.

Carrier, S. J. (2009). The effects of outdoor science lessons with elementary school students on preservice teachers' self-efficacy. Journal of Elementary Science Education, 21(2),35-48. 
Cox-Petersen, A. M. \& Pfaffinger, J. A. (1998). Teacher preparation and teacher-student interactions at a discovery center of natural history. Journal of Elementary Science Education, 10, 20-35.

Çokluk Ö., Şekercioğlu G. \& Büyüköztürk Ş. (2010). Çok değişkenli istatistik SPSS ve LISREL uygulamaları. Pegem Akademi Yayınları, Ankara.

Demir, M. K. (2007a). Sınıf öğretmeni adaylarının gözlem gezisi yöntemine bakış açılarının incelenmesi. Gazi Eğitim Fakültesi Dergisi, 27(3), 83-98.

Demir, M. K. (2007b). Sınıf Öğretmenlerinin Hayat Bilgisi ve Sosyal Bilgiler derslerinde gözlem gezisi yöntemini uygulama durumları. Türk Eğitim Bilimleri Dergisi, 5(2), 323-341.

Demirbaş, M. (2005). Fen Bilgisi Öğretiminde Sosyal Öğrenme Teorisinin Öğrenme Ürünlerine Etkisinin Incelenmesi. (Yayımlanmamış doktora tezi). Gazi Üniversitesi Eğitim Bilimleri Enstitüsü, Ankara.

Deniz Sünbül, S. (2006). Farklı Likert Tipi Ölçek Geliştirme Teknikleri İle Geliştirilen Tutum Ölçeklerinin Psikometrik Özelliklerinin Karşılaştırılması. (Yayımlanmamış yüksek lisans tezi). Mersin Üniversitesi Sosyal Bilimler Enstitüsü, Mersin.

DeWitt, J. \& Storksdieck, M. (2008). A short review of school field trips: Key findings from the past and implications for the future. Visitor Studies, 11(2), 181-197.

Dillon J., Rickinson, M., Teamey, K., Morris, M., Choi, M. Y., Sanders, D. \& Benefield, P. (2006). The value of outdoor learning: evidence from research in the UK and elsewhere. School Science Review, 87(320), 107-111.

Ekici, E., Taşkın Ekici, F. \& Kara, İ. (2012). Öğretmenlere yönelik bilişim teknolojileri öz-yeterlik algısı ölçeğinin geçerlik ve güvenirlik çalışması. Pamukkale Üniversitesi Ë̆itim Fakültesi Dergisi, 31(1), 53-65.

Ertaş, H., Şen, A.İ. \& Parmasızoğlu, A. (2011). Okul dışı bilimsel etkinliklerin 9. sınıf öğrencilerinin enerji konusunu günlük hayatla ilişkilendirme düzeyine etkisi. Necatibey Ĕgitim Fakültesi Elektronik Fen ve Matematik Eğitimi Dergisi, 5(2), 178-198.

Ferry, B. (1993). Science centers and outdoor education centers provide valuable experience for preservice teachers. Journal of Science Teacher Education, 4, 8588.

Gerber, B. L., Cavallo, A. M. L. \& Marek, E. A. (2001). Relationships among informal learning environments, teaching procedures and scientific reasoning ability. International Journal of Science Education, 23(5), 535- 549.

Göğebakan, Y. (2008). Sanat Tarihi öğretiminde gösteri yöntemi ile gezi-gözlem yönteminin bilginin kalıcılığı açısından karşılaştırılması. Gazi Eğitim Fakültesi Dergisi, 28(2), 197-220.

Griffin, J. \& Symington, D. (1997). Moving from task-oriented to learning-oriented strategies on school excursions to museums. Science Education, 81(6), 763-779. 
Güler, A. (2011). Planlı bir müze gezisinin ilköğretim öğrencilerinin tutumuna etkisi. İlkögretim Online, 10(1), 169-179.

Güven, A., Gazel, A. A. \& Sever, R. (2004). Tarih öğretmenlerinin gezi-gözlem uygulamalarında karşılaştıkları sorunlar. Kazım Karabekir Eğitim Fakültesi Dergisi, 9, 225-235.

Hacıfazlıŏlu, Ö., Karadeniz, Ş. \& Dalgıç, G. (2011). Eğitim yöneticileri teknoloji liderliği öz-yeterlik ölçeğinin geçerlik ve güvenirlik çalışması. Kuram ve Uygulamada Ĕ̆itim Yönetimi, 17(2), 145-166.

Hannu, S. (1993). Science Centre Education, Motivation And Learning In Informal Education. (Unpublished doctoral dissertation). Helsinki University Department of Teacher Education, Finland.

Howe, R. W. \& Disinger, J. F. (1988). Teaching environmental education using outofschool settings and mass media. Retrieved from http://www.ericdigests.org/pre9215/mass.htm, 15 May, 2011.

Kaptan, F. \& Korkmaz, H. (2002) Probleme dayalı öğrenme yaklaşımının hizmet öncesi fen öğretmenlerinin problem çözme becerileri ve öz yeterlik inanç düzeylerine etkisi. V. Ulusal Fen Bilimleri ve Matematik Eğitimi Kongresi, 16-18 Eylül 2002, Ankara.

Karasar, N. (1999). Bilimsel araştırma yöntemi. Anı Yayıncılık. Ankara.

Kete, R. \& Horasan, Y. (2013). Öğretmen adaylarının uygulamalı (Doğa merkezli) Biyoloji derslerinde verimlilikleri. VI. Ulusal Lisansüstü Eğitim Sempozyumu Bildiriler Kitabı II, Sakarya Üniversitesi Eğitim Bilimleri Enstitüsü, Sakarya.

Kılıç, Ç. \& İncikabı, L. (2013). Öğretmenlerin problem kurma ile ilgili öz-yeterlik inançlarının belirlenmesine yönelik ölçek geliştirme çalışması. Dumlupınar Üniversitesi Sosyal Bilimler Dergisi, 35, 223-234.

Kisiel, J. (2003). Teachers, museums, and worksheets: A closer look at learning experience. Journal of Science Teacher Education, 14, 3-21.

Kisiel, J. (2005). Understanding elementary teacher motivations for science fieldtrips. Science Education, 86(6), 936-955.

Knapp, D. \& Barrie, E. (2001). Content evaluation of an environmental science field trip. Journal of Science Education and Technology, 10(4), 351-357.

Lakin, L. (2006). Science beyond the classroom. Journal of Biological Education, 40(2), 88-90.

Melber, L. H. \& Abraham, L. M. (1999). Beyond the classroom: Linking with informal education. Science Activities, 36, 3-4.

Mercimek, O. \& Pektaş, M. (2013). İstatistiğe yönelik öz-yeterlik ölçeğinin geliştirilmesi. Kastamonu Ĕ̆itim Dergisi, 21(2), 759-776.

Michie, M. (1998). Factors influencing secondary science teachers to organize and conduct field trips. Australian Science Teacher Journal, 44, 43-50. 
Moseley, C., Reinke, K. \& Bookout, V. (2002). The effect of teaching outdoor environmental education on preservice teachers' attitudes toward self-eff icacy and outcome expectancy. The Journal of Environmental Education, 34(1), 9-15.

Berberoğlu, E. \& Uygun, S. (2013). Sınıf dışı eğitimin Dünyadaki ve Türkiye'deki gelişiminin incelenmesi. Mersin Üniversitesi Ĕ̆itim Fakültesi Dergisi, 9(2), 32-42.

Berberoğlu, E., Güder, Y., Sezer, B. \& Yalçın Özdilek, Ş. (2013). Sınıf dış1 hidrobiyoloji etkinliğinin öğrencilerin duyuşsal bakış açıları üzerine etkisi, örnek olay incelemesi: Çanakkale bilim kampı. Kastamonu Ĕgitim Dergisi, 21(3), 11771198.

Olson, J. K., Cox-Petersen, A. M. \& McComas, W. F. (2001). The inclusion of informal environments in science teacher preparation. Journal of Science Teacher Education, 12, 155-173.

Orion, N. \& Hofstein, A. (1994). Factors that influence learning during a scientific field trip in a natural environment. Journal of Research in Science Teaching, 31(10), 1097-1119.

Orion, N., Hofstein, A.,Tamir, P. \& Giddings, G. J. (1997) Devolopment and validation of an instrument for assesing the learning environment of outdoor science activities. Science Education, 81, 161-171.

Özdemir, A., Aydın, N. \& Akar Vural R. (2009). Çevre eğitimi öz-yeterlik algısı üzerine bir ölçek geliştirme çalışması. Dokuz Eylül Üniversitesi Buca Eğitim Fakültesi Dergisi, 26, 1-8.

Özgen, N. (2011). Fiziki Coğrafya dersi öğretim metoduna farklı bir yaklaşım: Gezigözlem destekli öğretim. Marmara Coğrafya Dergisi, 23, 373-388.

Öztürk, Ç. (2008). Coğrafya öğretiminde gezi-gözlem tekniğini kullanabilme özyeterlilik inanç ölçeğinin geliştirilmesi. Ondokuz Mayıs Üniversitesi Ĕ̆itim Fakültesi Dergisi, 25, 13-23.

Ramey-Gassert, L. (1997). Learning science beyond the classroom. The Elementary School Journal, 97(4), 433-448.

Rudman, C. L. (1994). A review of the use and implementation of science field trips. School Science and Mathematics, 94, 138-141.

Scherer, R. F., Wiebe F. A., Luther, D. C. \& Adams J. S. (1988). Dimensionality of coping: facor stability using the ways of coping questionnaire, Psychological Reports, 62(3),763-770. PubMed PMID: 3406294.

Simmons, D. (1998) Using natural settings for environmental education: Perceived benefits and barriers. Journal of Environmental Education, 29(3), 23-31.

Şahin, İ. (2009). Eğitsel internet kullanım öz-yeterliği inançları ölçeğinin geçerliği ve güvenirliği. Selçuk Üniversitesi Sosyal Bilimler Enstitüsü Dergisi, 21, 461-471.

Şencan, H. (2005). Sosyal ve davranışsal ölçümlerde güvenirlik ve geçerlilik. Seçkin Yayınc1lık, Ankara. 
Tal, R. T. (2004). Using a field trip as a guide for conceptual understanding in environmental education: A case study of a pre-service teacher's research. Chemical Education Research and Practice, 5, 127-142.

Tal, R., Bamberger, Y. \& Morag, O. (2005). Guided school visits to Natural History Museums in Israel: Teachers’ roles. Science Education, 89(6), 920-935.

Tal, T. \& Morag, O. (2009). Reflective practice as a means for preparing to teach outdoors in an ecological garden. Journal of Science Teacher Education, 20, 245262.

Tal, T. \& Steiner, L. (2006). Patterns of teacher-museum staff relationships: School visits to the educational center of a science museum. Canadian Journal of Science, Mathematics and Technology Education, 6, 25-46.

Tatar, N. \& Bağrıyanık, K.E. (2012). Fen ve Teknoloji dersi öğretmenlerinin okul dışı eğitime yönelik görüşleri. Illköğretim Online, 11(4), 883-896.

Tavşancıl E. (2005). Tutumların ölçülmesi ve SPSS ile veri analizi. Nobel Yayıncılık, Ankara.

Tavşancıl, E., (2002). Tutumların ölçülmesi ve SPSS ile veri analizi. Nobel Yayıncılık, Ankara.

Taylor, E. W., \& Caldarelli, M. (2004). Teaching beliefs of non-formal environmental educators: A perspective from state and local parks in the United States. Environmental Education Research, 10(4), 451-469.

Tortop H. S. \& Özek, N. (2013). Proje tabanlı öğrenmede anlamlı alan gezisi; Güneş enerjisi ve kullanım alanları konusu. Hacettepe Üniversitesi Ĕ̈itim Fakültesi Dergisi, 44, 300-307.

Tuckman,B. W. \& Sexton, T. L. (1990). The relationship between self- beliefs and selfregulated performance. Journal of Social Behavior and Personality, 5, 465-472.

Turan, S. \& Demirel, Ö. (2009). Probleme dayalı öğrenmeye ilişkin tutum ölçeği geçerlik ve güvenirlik çalışması. Eğitim ve Bilim, 34(152): 15-29.

Türkmen, H. (2010). İnformal (Sınıf-Dışı) Fen Bilgisi eğitimine tarihsel bakış ve eğitimimize entegrasyonu. Çukurova Üniversitesi Ĕ̆itim Fakültesi Dergisi, 3(39), 46-59.

Wellington, J. (1990). Formal and informal learning in science: The role of the interactive science centres. Physics Education, 25, 247-252.

Yaman, S., Cansüngü, Ö. \& Altunçekiç, A. (2004). Fen bilgisi öğretmen adaylarının özyeterlik inanç düzeylerinin incelenmesi üzerine bir araştırma. Türk Eğitim Bilimleri Dergisi, 2(3), 355-364.

Yavuz, M. \& Kıyıcı, F. B. (2012). İnformal öğrenme ortamlarının ilköğretim öğrencilerinin fene karşı kaygı düzeylerinin değişmesine ve akademik başarılarına etkisi: Hayvanat bahçesi örneği. X. Ulusal Fen Bilimleri ve Matematik Eğitimi Kongresi Özet Kitabı. Niğde Üniversitesi Eğitim Fakültesi, Niğde, 106. 


\section{EK 1.}

Okul Dışı Çevrelere Eğitim Amaçlı Gezi Düzenleyebilme Öz-Yeterlik İnancı Ölçeği İçin Örnek Maddeler

\begin{tabular}{|c|l|}
\hline $\mathbf{1}$ & Gezi yerinde öğrencilere rehberlik etmekte zorlanırım \\
\hline $\mathbf{1 0}$ & Öğrenci sayısı fazla olsa bile gezi alanında kontrolü sağlayabilirim \\
\hline $\mathbf{1 2}$ & Gezi sonrasında gezinin amaçlarına ne derece ulaştığının tespit etmede zorluk çekerim \\
\hline $\mathbf{1 4}$ & Gezi yerinin genelini ya da odaklanılacak obje/leri dersle ilişkilendirmede zorluk çekerim \\
\hline $\mathbf{1 7}$ & Gezi esnasında öğrencilerin eleştirel düşünme becerilerini geliştirebilirim \\
\hline $\mathbf{2 0}$ & $\begin{array}{l}\text { Gezi öncesi plan (gidiş yolu, süresi, ulaşım vasıtaları, hareket saatleri, öğrenci sayıları, } \\
\text { gezi ücretleri vs.) hazırlamada zorlanacağımı düşünüyorum }\end{array}$ \\
\hline 21 & $\begin{array}{l}\text { Geziden döndükten sonra geziyi öğrencilerimle değerlendirmede (tartı̧ma, proje, kompozisyon } \\
\text { vs.) zorluk çekmem }\end{array}$ \\
\hline 22 & $\begin{array}{l}\text { Gezi sürecinde kullanılacak olan araçların (tanıtım broşürü, çalışma yaprakları, bilgi testleri vs.) } \\
\text { hazırlanmasında zorlanmam }\end{array}$ \\
\hline 23 & $\begin{array}{l}\text { Bir günden fazla sürecek geziler için öğrencilerin konaklama ihtiyaçlarını } \\
\text { giderebileceğimden emin değilim }\end{array}$ \\
\hline 25 & Okul dışı çevrelere çok rahatlıkla gezi düzenleyebileceğime inanıyorum \\
\hline $\mathbf{2 8}$ & Gezi için gerekli izinlerin alınmasında (öğrenci velileri, okul idaresi vs.) güçlük çekerim \\
\hline 30 & $\begin{array}{l}\text { Gezi öncesi öğrencilere gerekli açıklamaları (niçin gidilecek, ne tür çalış̧alar yapılacak, } \\
\text { uyulması gereken kurallar vs.) yaparken yetersiz kalabilirim }\end{array}$ \\
\hline 34 & Gezide çekilen fotoğrafların okul panolarında sergilenmesi noktasında güçlük çekerim \\
\hline 36 & Öğrenci ailelerine yapılmış olan geziyle ilgili bilgi vermede zorlanmam \\
\hline 37 & $\begin{array}{l}\text { Gezi yerinden (varsa) randevuların alınması ve gezi yerindeki yetkililerin bilgilendirilmesinde } \\
\text { (öğrenci sayısı, gezi günü, saati vs.) güçlük çekmem }\end{array}$ \\
\hline 39 & Okul dışı çevrelere gezi düzenlemek için yeterli tecrübeye sahip olduğumu düşünüyorum \\
\hline
\end{tabular}

